\title{
KOMPUTASI BERBASIS DINAMIKA FLUIDA DALAM PREDIKSI PERFORMA PREDUSTER SECARA UNSTEADY STATE
}

\author{
Eka Lutfi Septiani \\ eka.septiani@uisi.ac.id \\ Departemen Teknik Kimia, Universitas Internasional Semen Indonesia
}

\begin{abstract}
Abstrak
Preduster merupakan alat berbentuk cyclone yang digunakan dalam memisahkan gas dan padatan. Dalam industri semen, alat ini dipasang untuk memisahkan partikel debu dan udara panas sisa pembakaran dan pemanasan sehingga udara panas tersebut dapat dimanfaatkan kembali sebagai media pra-pemanasan bahan baku maupun media pengering batu bara. Komputasi berbasis dinamika fluida telah digunakan dalam penelitian ini karena mampu menyelesaikan persamaan perpindahan momentum, panas maupun massa. Pemodelan sistem unsteady state menggunakan algoritma Large Eddy Simulation (LES) dengan time step 0,01 selama 10 detik. Pendekatan distribusi partikel yang masuk dalam preduster menggunakan model Lagrangian. Performa preduster dinilai dari efisiensi pemisahan solidnya, pemodelan ini memprediksi efisiensi pemisahan yang terjadi selama 10 detik mencapai $70,9 \%$.
\end{abstract}

Kata kunci: Cyclone, Komputasi Dinamika Fluida, Large Eddy Simulation, model Lagrange, Efisiensi

\section{Pendahuluan}

Cyclone merupakan alat pemisah antara gas dan padatan [1] yang memiliki banyak keunggulan yaitu biaya instalasi dan perawatan relatif lebih rendah dibandingkan dengan alat lainnya, dapat dioperasikan pada temperature yang tinggi, serta efisiensi pemisahannya sangat tinggi. Namun, alat ini tidak terlalu baik dalam pemisahan gas dan solid yang berukuran sangat kecil $[2,3]$. Salah satu cyclone yang dipasang dalam industri semen difungsikan sebagai preduster yakni alat untuk mengurangi kandungan solid dalam gas. Udara panas sisa pembakaran dalam klinker dan kalsiner dapat digunakan sebagai media pemanas dalam alat preheater empat tingkat, selanjutnya dimanfaatkan kembali sebagai media pengering batubara didalam coalmill agar kandungan air dalam batubara yang diumpankan untuk pembakaran di klinker dan kalsiner berkurang. Hal ini bertujuan untuk meningkatkan efisiensi pembakaran, tetapi hasil pembakaran masih belum optimal yang kemungkinan disebabkan oleh kandungan debu dalam batubara relative tinggi berdasarkan hasil pengamatan. Tingginya kandungan debu ini diduga berasal dari pemisahan udara panas dengan padatan debu yang kurang maksimal didalam preduster.

Kajian performa cyclone dalam skala industri secara eksperimen sangat susah untuk dilakukan terkait dengan waktu dan biaya yang cukup tinggi sehingga dalam penelitian ini dilakukan prediksi secara numeric berbasis dinamika fluida. Beberapa peneliti terdahulu telah menunjukkan bahwa prediksi secara numeric berbasis dinamika fluida dapat diterima dan memberikan kesesuaian dengan hasil eksperimen karena dalam pendekatan numerik ini menyelesaikan persamaan perpindahan momentum, panas, dan massa [4]. Kepa [5] menunjukkan bahwa pemodelan berbasis dinamika fluida dengan Reynold Stress Model (RSM) dapat merepresentasikan performa cyclone dalam skala besar yang sulit dilakukan. Brennan et. al. [6] mencoba membandingkan pemodelan Differential Raynold Stress (DRSM), Large Eddy Simulation (LES), dan model laminer flow. Hasil yang diperoleh menunjukkan bahwa model DRSM dan LES memberikan hasil yang sangat mendekati eksperimen. Model LES telah banyak menunjukkan kesesuaian dalam prediksi numerik meskipun memerlukan daya komputasi yang besar[7-9]. Oleh karena itu, dalam memprediksi preduster dalam industri semen ini dilakukan dengan pemodelan LES. Berdasarkan pemodelan ini akan dihitung efisiensi pemisahan dari preduster.

\section{Metode}

Penyelesaian secara numerik berbasis dinamika fluida pada penelitian ini menggunakan software Ansys Fluent Student Version 16.2. Terdapat tiga tahapan dalam penyelesaian ini, yaitu tahap preprocessing, solver, dan tahan post-processing. Pada tahap pre-processing diharuskan membuat domain perhitungannya dan mendefinisikan bagian-bagian dari domain perhitungan untuk penentuan kondisi batas nantinya. Domain dalam tahap ini berupa zona 3-Dimensi yang dibuat dengan menggunakan software Workbench Design Modeller mengikuti dimensi yang ada dalam industri 
semen seperti Gambar 1.(a), selanjutnya dilakukan pendefinisian yang akan digunakan untuk kondisi batas dan pemecahan volume domain menjadi 84.148 buah hexagonal seperti yang terlihat dalam Gambar 1.(b). Pemecahan volume dilakukan karena penyelesaian ini menggunakan pendekatan metode finite volume.

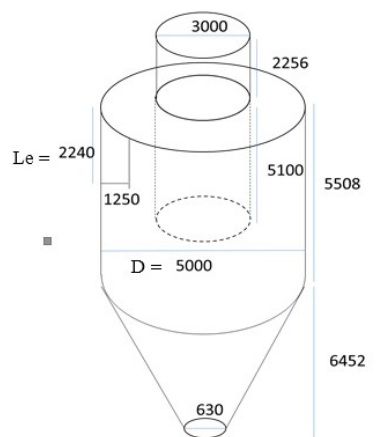

(a)

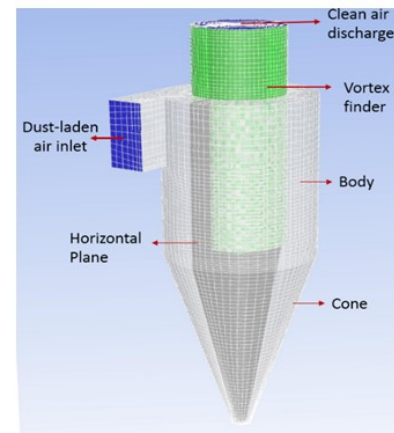

(b)

Gambar 1. (a) Geometri preduster pada industri semen ( $\mathrm{mm}$ ), (b) Pembagian volume dan definisi dalam kondisi batas

Analisa nilai skewness pada geometri ini diperoleh 0,153 , menunjukkan bahwa pembagian volume domain ini sangat baik karena dibawah 0,25.

Tahapan kedua ialah solver yakni penentuan pemodelan. Penelitian ini menggunakan model turbulensi LES yang merupakan alternatif pertengahan dari pemodelan Reynold Average Navier Stokes(RANS) dan Direct Numerical Simulation(DNS). Model ini menyelesaikan persamaan momentum berupa filtered Navier Stokes [10] sebagai berikut :

$$
\frac{\partial \bar{u}_{i}}{\partial t}+\frac{\partial}{\partial x_{j}}\left(\bar{u}_{i} \bar{u}_{j}\right)=-\frac{1}{\rho} \frac{\partial \bar{p}}{\partial x_{i}}+2 v \frac{\partial}{\partial x_{i}} \bar{S}_{i j}-\frac{\partial \tau_{i j}^{r}}{\partial x_{j}}
$$

Pemodelan turbulensi skala sub-grid dalam Ansys Fluent menggunakan hipotesa Boussinesq yang dihitung dari :

$$
\tau_{i j}-\frac{1}{3} \tau_{k k} \delta_{i j}=-2 \mu_{t} \bar{S}_{i j}
$$

Harga $\tau_{k k}$ tidak dimodelkan, laju strain tensor didefinisikan dengan

$$
\bar{S}_{i j} \equiv \frac{1}{2}\left(\frac{\partial \bar{u} i}{\partial x j}+\frac{\partial \bar{u} j}{\partial x i}\right)
$$

Nilai persamaan Favre Filtered Navier-Stokes didefinisikan dalam suku yang berbeda yaitu isotropic dan deviatoric:

$$
\tau_{i j}=\tau_{i j}-\frac{1}{3} \tau_{k k} \delta_{i j}+\frac{1}{3} \tau_{k k} \delta_{i j}
$$

Suku deviatoric dimodelkan dengan model Smagorinsky yakni

$$
\tau_{i j}-\frac{1}{3} \tau_{k k} \delta_{i j}=-2 \mu_{t}\left(S_{i j}-\frac{1}{3} S_{k k} \delta_{i j}\right)
$$

suku $\tau_{\mathrm{kk}}$ dapat ditulis sebagai $\tau_{k k}=\gamma M^{2}{ }_{s g s} \bar{p}$ dimana Msgs adalah Mach Number. Model pertama yang telah dibuat Smagorinsky ialah model Smagorinsky-Lilly dimana viskositas pusaran dimodelkan dengan $\mu_{\mathrm{t}}=\rho L_{s}^{2}|\bar{S}|$, Ls ialah panjang gabungan dari skala sub-grid dan $|\bar{S}| \equiv \sqrt{2 \bar{S}_{i j} \bar{S}_{i j}}$. Didalam Ansys Fluent Ls is dikalkulasikan dengan $L s=\min (k d, C s \Delta)$ dimana $\mathrm{k}$ adalah konstanta Von Karman c, d adalah jarak terdekat dengan dinding, $\mathrm{Cs}=0.1$ adalah konstanta Smagorinsky, dan $\Delta$ adalah skala grid lokal yang dihitung dengan $\Delta=\mathrm{V}^{3}$.

Untuk pemodelan partikel menggunakan lagrangian model dengan distribusi partikel mengikuti pemodelan Rossin-Rammler yang diinjeksikan sebnyak $10 \%$ dari udara panas yang masuk melalui inlet preduster.

Hasil perhitungan dianalisa pada tahap terakhir yaitu post-processing. Dalam tahap ini dilakukan observasi data tekanan, distribusi partikel sepanjang waktu tampak dari atas dan samping preduster, dan garis lintasan partikel didalam cyclone. 


\section{Hasil dan Pembahasan}

Pendeketan Unsteady State dengan pemodelan LES dan Lagrangian dilakukan selama 10 detik dengan time step 0,01 dan jumlah time step 1000. Tekanan pada aliran gas keluar dibandingkan dengan tekanan yang terdapat dalam mill batubara. Tekanan preduster pada hasil prediksi ini diperoleh -3205 Pa dimana terdapat perbedaan dengan yang terbaca pada mill batubara yaitu 2546,5 $\mathrm{Pa}$. Perbedaan ini cukup masuk akal karena prediksi tekanan pada kalkulasi hanya sampai outlet gas pada preduster sehingga memungkinkan terjadi perbedaan tekanan dikarenakan friksi sepanjang saluran dari peduster ke mill batubara.

Pada hasil pengamatan secara unsteady state yang direkam dalam waktu satu detik pertama menunjukkan pemodelan dengan LES memberikan kesesuaian dalam teori aliran fluida didalam cyclone. Partikel debu yang ikut masuk dalam aliran udara masuk kedalam preduster melalui samping, akibatnya debu mengalami gaya sentripetal didalam preduster sehingga pemisahan antara udara dan debu dapat terjadi. Udara akan terus berputar membentuk vorteks yang berputar didalam silinder preduster, sedangkan debu yang terikut seharusnya terlempar menuju dinding preduster. Udara yang berputar dari atas menuju ke bawah berubah menjadi pusaran yang menuju ke atas akibat perubahan bentuk silinder menjadi bentuk konis. Debu yang terpisah oleh udara jatuh ke bawah untuk dikumpulkan.

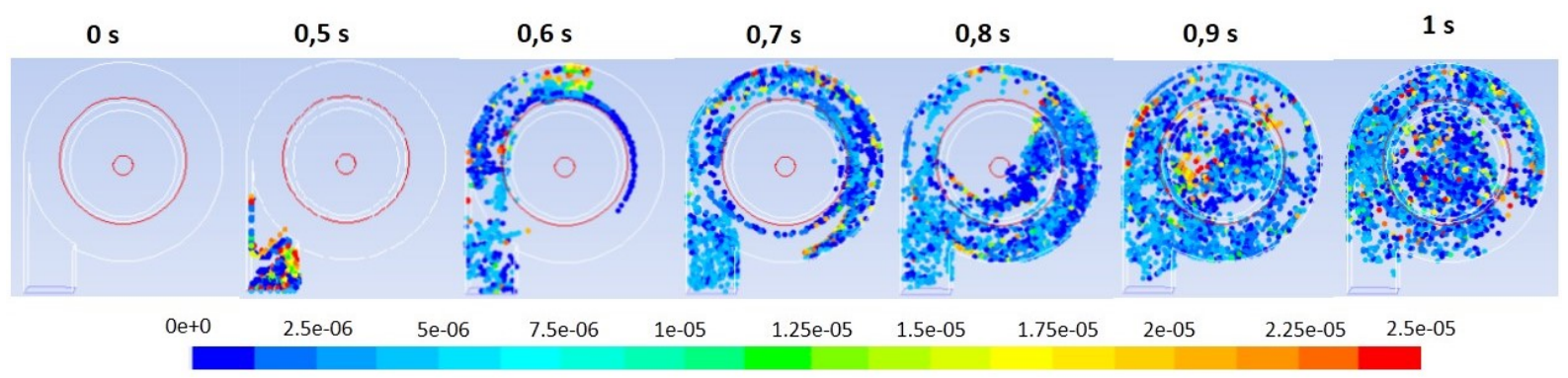

Gambar 2. Tampak Atas: Simulasi Persebaran Partikel Debu Unsteady State pada 1 detik pertama (ukuran dalam skala meter)

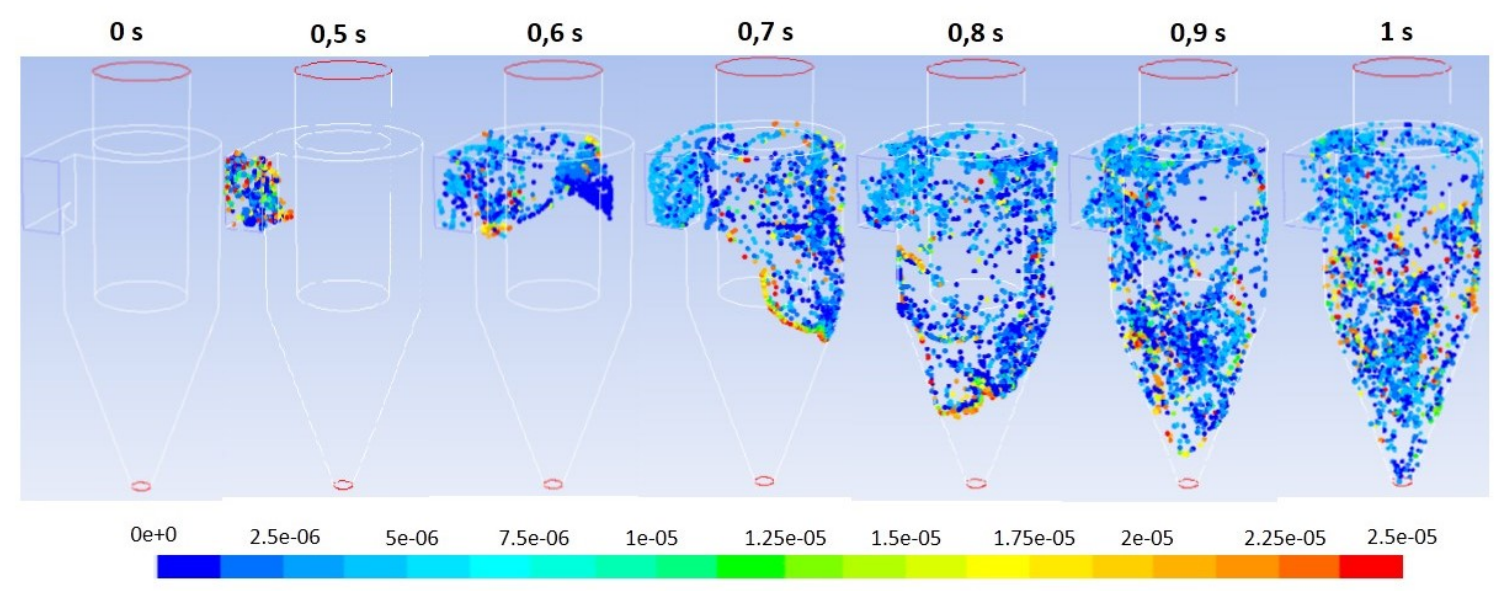

Gambar 3. Tampak Samping: Simulasi Persebaran Partikel Debu Unsteady State pada 1 detik pertama (ukuran dalam skala meter)

Pada simulasi diatas satu detik, sebagian besar partikel yang sangat kecil dengan rata-rata dibawah $1 \mu \mathrm{m}$ ikut terbawa aliran udara panas dalam outlet gas bersih. Oleh karena itu dalam analisa perhitungan efisiensi pemisahan dalam preduster diperoleh $70,9 \%$ dengan mengikuti persamaan :

$$
\begin{aligned}
& \eta_{o}=\sum \eta_{j} m_{j} \\
& \eta_{j}=\frac{1}{1+\left(\frac{d_{p c}}{d_{p j}}\right)^{2}}
\end{aligned}
$$




$$
d_{p c}=\left[\frac{9 \mu W}{2 \pi N e V_{i}\left(\rho_{p}-\rho_{g}\right.}\right]^{2}
$$

$m_{j}$ adalah fraksi massa partikel didalam rentang ukuran partikel ke-j. $d_{p j}$ adalah karakteristik diameterdari rentang ukuran partikel ke-j (dalam $\mu \mathrm{m}$ ). Ne bilangan kembali dan Vi adalah kecepatan inlet.

\section{Kesimpulan dan saran}

Dalam penelitian ini dilakukan evaluasi performa preduster secara numeric berbasis dinamika fluida menggunakan pemodelan LES dan Lagrangian. Dari hasil yang diperoleh terdapat kesesuaian hasil simulasi dengan pola alir teoritis, selain itu tekanan yang diperoleh secara numerik dapat diterima bila dibandingkan dengan tekanan pada mill batubara dalam industri semen. Dari kesesuain ini, maka dapat dilakukan perhitungan efisiensi pemisahan berdasarkan pengamatan 10 detik yakni sebesar $70,9 \%$. Dalam penelitian berikut perlu dilakukan pengamatan yang lebih lama apakah terdapat peningkatan atau penurunan perhitungan efisiensi, apabila terdapat penurunan perhitungan maka selanjutnya dapat dilakukan tahapan optimasi dengan mempertimbangan berbagai faktor seperti kecepatan fluida, laju alir, dan dimensi preduster.

\section{Terima Kasih}

Ucapan terima kasih telah disampaikan pada LPPM UISI dalam hal dukungan finansial penelitian dan kepada PT Semen Indonesia, (Persero) Tbk. dalam hal dukungan data yang diberikan.

\section{Daftar Pustaka}

[1] Geankoplis, C.J. 2003. Transport Processes and Separation Process Principle. Pearson Education, Inc. Bab 14, hal. 943.

[2] Kosaki, Y., Hirai, T. , Yamanaka, Y., Takeshima, K. 2015. Investigation on dust collection and particle classification performance of cyclone by airflow control for design of cyclones. J. Powder Technology 277, 22-35

[3] F. Ficici, V. Ari, M. Kapsiz. 2010. The effects of vortex finder on the pressure drop in cyclone separators International Journal of the Physical Sciences Vol. 5 (6), p. 804-81

[4] Anonim, ANSYS FLUENT 14.0 Teory Guide ( ANSYS Inc, Canonsburg 2011)

[5] Kepa. 2013. The efficiency improvement of a large-diameter cyclone - The CFD calculations. J. Separation and Purification Technology 118, 105-111

[6] Brennan, M., Holtam, P., Narasimba, M. 2014. A semi-mechanistic model of hydrocyclonesDeveloped from industrial data and inputs from CFD. International Jpurnal of Minerals Process $133,1-12$.

[7] Derksen, J.J., Van den Akker, H.E.A., Sundaresan, S. 2008. Two-way coupled large-eddy simulations of the gas-solid flow in cyclone separator. AIChE J. 54 (4) 872.

[8] Souza F.J., Salvo R.V. and Martins D.A.M. 2012. Large Eddy Simulation of the gas-particle flow in cyclone separators. J. Separat. Purificat. Technol. 94, 61.

[9] Septiani, E. L., Widiyastuti, W., Winardi, S., Machmudah, S., Nurtono, T., Kusdianto. 2016. Effect of turbulence modelling to predict combustion and nanoparticle production in the flame assisted spray dryer based on computational fluid dynamics. Padjadjaran International Physics Symposium 2016. AIP Conference Proceedings, 1712, 040002

[10] Versteg H. K. and Malalasekera W. 2007 An introduction to computational fluid dynamics(England: Pearson Education Limited) 